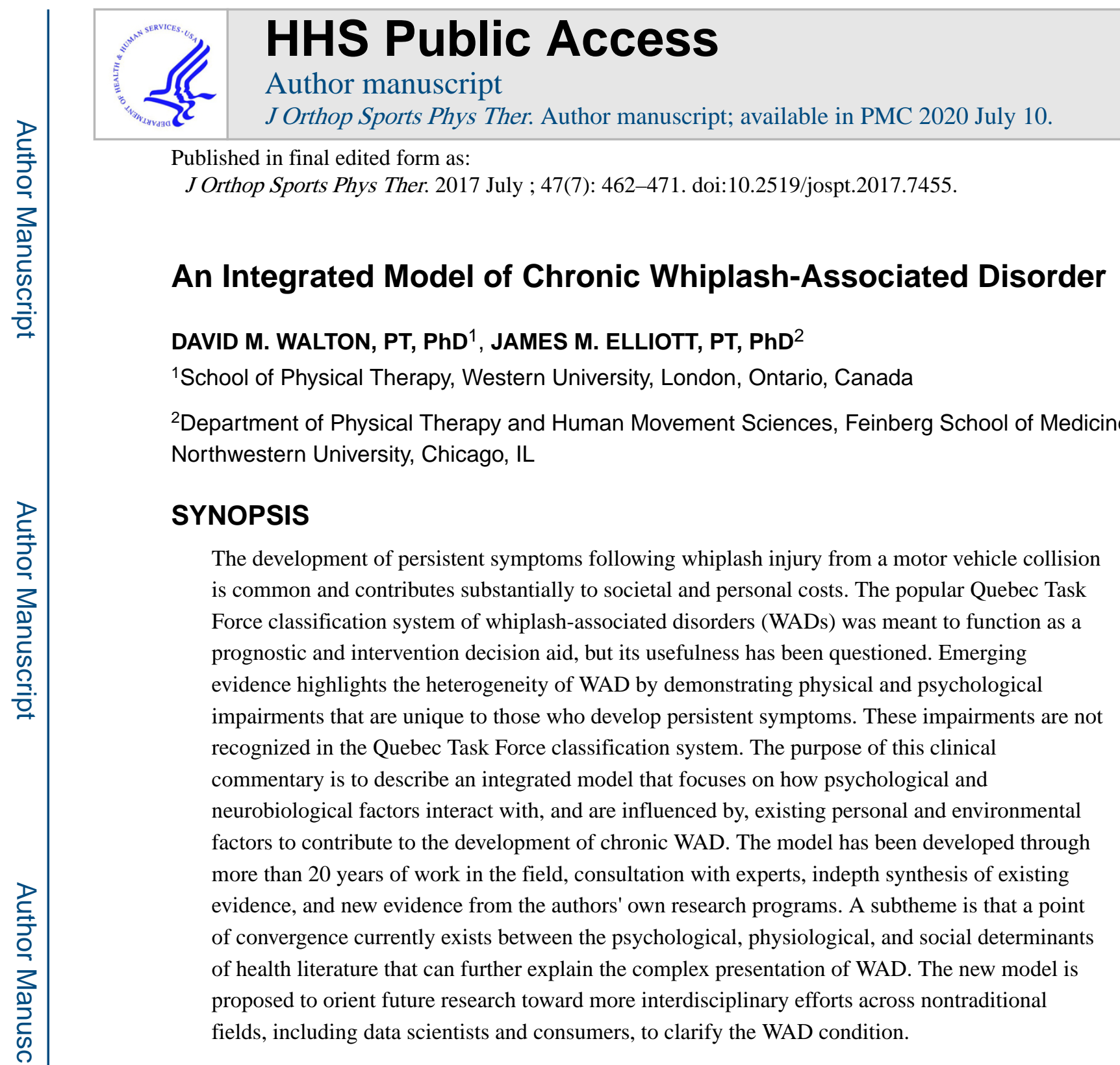

\title{
Keywords
}

acute pain; cervical spine; chronic pain; diathesis; neck; WAD

\begin{abstract}
Whiplash-associated disorder (WAD) is the most common outcome of noncatastrophic motor vehicle collisions (MVCs). ${ }^{19,89}$ Of those experiencing WAD from an MVC, $20 \%$ to $50 \%$ will continue to report persistent interference in daily life 12 months later. ${ }^{19}$ The economic burden from MVCs is disproportionately high, with annual costs of $£ 3$ billion in the United Kingdom ${ }^{47}$ and an estimated $\$ 42$ billion in the United States for nonfatal
\end{abstract}

\footnotetext{
Address correspondence to Dr David Walton, Room EC1443, Western University, 1201 Western Road, London, Ontario, Canada N6G 1H1.dmwalton5@gmail.com.

Dr Elliott's relevant activities outside the submitted work include board membership and ownership/investment interest in a medical consulting company, Pain ID, LLC. Dr Walton's relevant activities outside the submitted work include ownership of David Walton Rehabilitation Education, Consulting and Research, a small private business focusing on professional development and clinical physical therapy consultation. He is an Associate Editor for Musculoskeletal Science and Practice. The authors certify that they have no affiliations with or financial involvement in any organization or entity with a direct financial interest in the subject matter or materials discussed in the article.
} 
injuries.76 Neck pain of traumatic and nontraumatic origins is the fourth leading cause of years lived with disability globally.72 Alarmingly, this was the exact rank for neck pain in 1990,73 suggesting that research in to the prevention and rehabilitation of neck pain over the past 25 years has had little effect on its relative overall global burden.

The mechanisms that explain recovery from or persistence of WAD remain unclear. Existing evidence has highlighted several predictors of the transition from acute to chronic WAD, such as female sex, older age, higher initial self-rated pain intensity, higher disability, and a host of cognitive factors (eg, fear, catastrophizing, low expectations for recovery). ${ }^{116,117,119}$ Interestingly, current evidence suggests that the mechanics of the event itself, such as speed and direction of impact, awareness of impending collision, or airbag deployment, have little to no effect on the postinjury course of recovery.117 As a result, the current thrust of research in the field appears to be focused on posttraumatic affect and cognitions, with a strong focus on the psyche. ${ }^{13,14,26,60,79,111,112}$ However, we argue that full understanding of the mechanisms to explain the experience of WAD must go beyond implying that sufferers are "thinking wrong." It is our position that a reconceptualization of WAD as a multisystem stress- and tissue-based interaction moderated by contextual factors is required to achieve a better mechanistic understanding of patient-centered outcomes.

In the spirit ot established models, ${ }^{42,96,109,111,112}$ a new model is presented that respects prior knowledge while proposing new pathways and interactions intended to propel the field forward. This new model conceptualizes trauma as an event that is both potentially injurious and distressing, influenced by existing vulnerabilities or resiliencies of the person and the socioenvironmental context within which the person lives and functions. Central to the thesis is that there is no single threshold of a "good" or "bad" reaction to trauma that can be applied universally to all people; rather, it is only when the combination of individual vulnerabilities and psychological and neurobiological processes exceeds a person-specific threshold that a person is at risk of developing chronic WAD. The purpose of this paper is to present the new model along with a comprehensive overview of existing evidence.

\section{WHY IS A NEW MODEL NEEDED?}

A new wad conceptualization feels particularly timely, as policy makers the world over appear to struggle with how best to interpret and implement evidence (or lack thereof) for WAD diagnosis and treatment. A new series of health care reforms in the United Kingdom, for example, are explicitly designed to deincentivize WAD claims, ${ }^{110}$ suggesting a presupposition that many claims are the result of exaggeration and secondary gain. We opine that such reforms are premature, unlikely to result in overall reduced burden, and will unfairly penalize injured people to the point of limiting their access to needed care and justice.

\section{PRIOR KNOWLEDGE}

\section{Pathoanatomical Lesions}

Attempts to explain the PHEnomenon of chronic or persistent WAD are decades old. Momentum in the search for pathoanatomical lesions increased toward the end of the 20th 
century. ${ }^{49,51,55,57,58,82,105}$ The facet joints enjoyed the greatest empirical support as peripheral drivers of chronic WAD-related pain., ${ }^{4,64,65} \mathrm{In}$ an oft-cited randomized trial, Lord and colleagues ${ }^{66}$ found that of 54 patients with chronic WAD, 24 (44\%) responded to a medial branch block procedure intended to identify pain of primarily facetogenic origin. Those respondents were randomized to a verum-versus-sham radiofrequency neurotomy procedure (12 patients per arm). While both groups initially reported pain relief, the verum group enjoyed significantly longer improvement. ${ }^{66}$ This led to a prevailing view that chronic WAD was reducible to peripheral drivers. This study was followed by a secondary analysis using psychological measures as the outcome. ${ }^{115}$ After excluding 7 of the 24 patients for pain at more than 1 joint, 9 of the remaining 17 were pain free 3 months later, whereas 8 remained symptomatic. All 9 of those who reported being pain free and who initially presented with psychopathology met the criteria for complete resolution of psychological distress at the 3-month follow-up, while only 1 of the 8 with persistent pain reported the same extent of resolution. These findings led the authors to opine that "the psychological distress exhibited by these patients was a consequence of the chronic somatic pain," 115 with strong endorsement of the pathoanatomical model of chronic WAD. Despite the small sample and lack of reproduction, this pair of papers has had considerable impact on the practice of interventional medicine for chronic WAD. ${ }^{66,115}$ More recently, Smith and colleagues $^{94,95}$ used a robust set of secondary outcomes in a noncontrolled observational cohort study $(n=46)$ to find similar temporal relationships between concomitant reduction (and subsequent return) of chronic WAD-related pain and psychological distress. ${ }^{95}$ While it is difficult to draw definitive conclusions from a small body of knowledge, the existing data suggest that $40 \%$ to $45 \%$ of people with chronic WAD may indeed have symptoms originating from a peripheral articular lesion and that, in some, these painful lesions may cause affective distress. Assuming these results are generalizable, this suggests that peripheral drivers (termed tissue in the new model) may explain persistent symptoms in at least a subgroup of patients, which is worthy of clinical evaluation. But even under the best conditions, it still leaves the majority without clear explanation or understanding of their symptoms.

Other tissues targeted in the empirical search for a peripheral lesion (1995-2005) included the upper cervical ligaments, ${ }^{50,55,56}$ the trigeminal nucleus, ${ }^{99}$ and tears in the dura mater around the cord. ${ }^{45}$ While the published literature includes evidence in support of such lesions, several have been subsequently refuted, ${ }^{74,75}$ and none have achieved the mantle of "silver bullet lesion." It has become clear that purely tissue-based models are unable to satisfactorily explain the experience and presentation of WAD.

\section{The Quebec Task Force Classification System}

It was during this same decade (19952005) that the Quebec Task Force (QTF) published its monograph on whiplash, presenting for the first time the term whiplash-associated disorder. ${ }^{96}$ Reflecting the thinking of the time, the 5 WAD classifications (TABLE) were dependent entirely on clinical signs, where the drivers of pain and related disability were implied to be peripheral lesions. Here again, while there is some evidence that those with signs of neurological involvement (WAD III) recover more slowly than those with only restricted mobility (WAD II), and that both fare less well than those with only point tenderness (WAD 
I), ${ }^{119}$ consistent findings since then indicate that the QTF classification does not adequately represent the heterogeneity of the condition. ${ }^{43,97}$ While the 5 broad WAD categories of the QTF classification appear to be entrenched in the common lexicon of the field after 20 years, refinement is clearly needed.

\section{The Fear-Avoidance Model}

Looking to the pain literature more broadly, a number of models have emerged to explain the acute-to-chronic pain transition. Arguably the most well known is the fear-avoidance (FA) model. ${ }^{60}$ The FA model proposes 2 possible pathways after the experience of injury and pain: one driven by a lack of fear, active confrontation of pain, and resolu tion, and the other driven by catastrophic thoughts about pain, fear, withdrawal, hypervigilance, disuse, depression, disability, and more pain in a self-sustaining "vicious cycle." This model can be credited for considerable progress in chronic pain research, prompting clinicians and researchers to acknowledge that the existence of chronic pain need not be verified through observable peripheral lesions on diagnostic imaging. In some arenas, this model has validated the experience of chronic pain, but an unfortunate side effect appears to be an increasingly pervasive belief that chronic pain after injury is a condition of the weak willed or misinformed. ${ }^{77,84}$

Despite its ubiquity, the unidirectional and causal nature of the FA model has been challenged in recent years. Wideman and colleagues ${ }^{121}$ statistically refuted the sequential nature of the model, but supported catastrophizing as an important predictive variable. Nieto and colleagues ${ }^{79}$ used regression modeling to find that catastrophizing did predict disability in a cross-sectional study of people with subacute WAD, but that the association was mediat ed by fear of movement. Pedler and colleagues ${ }^{86}$ conducted longitudinal modeling to find that fear of movement, posttraumatic stress symptoms, and sensory hypersensitivity provided the best explanatory fit for a model predicting disability. Bousema and colleagues ${ }^{11}$ explored the deconditioning hypothesis in a prospective sample with acu te low back pain and found no consistent reduction in quantified metrics of physical condition in those who failed to recover after 1 year. These and other findings generally support the association of maladaptive cognitions and coping behaviors with subsequent disability, but a causal relationship has yet to be clearly established.

One way to establish a cause-and-effect relationship is to demonstrate the reversibility of the condition by cessation of exposure, such that removal of the cause should reduce the effect. ${ }^{44}$ If negative affect or maladaptive cognitions directly cause the development of chronic pain, then interventions to improve those factors should result in better outcomes. To this end, however, the evidence has been equivocal. Jull and colleagues ${ }^{48}$ conducted a 12-month pragmatic randomized controlled trial for individuals with acute WAD that included an early psychological intervention in those with high posttraumatic distress, but found that it provided no added statistical benefit compared to a usual-care control condition. Lamb and colleagues $^{59}$ also conducted a large pragmatic trial that included cognitively informed physical therapy compared wi th a single session of advice and education and found no meaningful difference in long-term outcomes. Collectively, the current state of knowledge appears to support a hypothesis that can be simplified to state that those who rate their 
experience as more terrible in the acute posttraumatic phase are more likely to continue to rate the experience as terrible when followed up, but the mechanisms to explain this transition (beyond a propensity to circle high numbers on a questionnaire) remain a mystery.

Notable by their absence in the FA model are "diatheses," defined as specific pre-existing vulnerabilities that influence the individual reaction to pain, stress, or illness. The FA model starts at the event (injury), which, while elegant in its simplicity, may oversimplify the mechanisms of post-WAD trajectories. For this, we turn to Turk's diathesis-stress model of chronic pain development ${ }^{109}$ to arrive at a more holistic model from which to develop new research questions.

\section{DIATHESIS-STRESS MODEL}

Dlathesis is a tendency to suffer from a particular medical condition. Turk's diathesis-stress model of chronic pain ${ }^{109}$ represents a useful additional consideration for a refined WAD model, suggesting that all people who experience trauma do so through a personal and contextual background that provides either protection from or vulnerability to the experience and subsequent development of persistent pain. The "diatheses" in Turk's model were again largely psychological (eg, the injured person's anxiety sensitivity, or a tendency to catastrophize over the symptoms of anxiety) and have received some empirical support in patients postsurgery. ${ }^{67}$ While psychological reaction is important, we believe that distress should be considered from both psychological and physiological perspectives. Germane to this thesis is a perspective that the experience of an MVC is a unique stressor in adult life that deserves specific attention.

\section{A NEW INTEGRATED MODEL}

The FIGURE presents our new integrated, biopsychosocial model describing potential mechanisms for the onset and maintenance of persistent pain and disability following acute trauma (eg, MVC). Readers will note both similarities and differences between this new model and the original FA model. ${ }^{11,112}$ In the new model, both physiological and social/ contextual variables have been included, and the dependence on physical deconditioning as a prerequisite for chronic pain and disability has been removed.

The model still posits 2 different trajectories on which an individual may travel following a traumatic event, but in this proposed model these trajectories are not fixed. A large bidirectional arrow allows those initially on an unfavorable trajectory to shift toward a more favorable one, and vice versa (FIGURE). Importantly, the model shifts from a focus on cognitive processes and behaviors of confrontation versus avoidance to a more holistic view of health and wellness that includes individual diathetic factors.

\section{Diatheses in the New Model}

Genetics, diet, exercise history, and prior injury or trauma likely all interact to affect the health of tissues, making them more or less resilient to rapid loading, such as that experienced during an MVC event. Psychological diatheses would include Turk's example ${ }^{109}$ of anxiety sensitivity as a trait of the individual, and could also include 
propensity to catastrophize about pain (a phenomenon that may be conceptualized as a s table trait of the person or as a reaction to pain ${ }^{101,113}$ ) and preinjury emotional status or psychopathology, such as pre-existing depression, anxiety, or related mental health disorders. Genetic diatheses in this context could include a growing list of polymorphisms that affect tissue health, stress reactivity, immune and inflammatory function, and vulnerability to new-onset psychopathology that continue to be identified, recognized, and defined. ${ }^{8,9,61,62,68,69}$ As examples directly relevant to this model, catechol- $O$ methyltransferase, an enzyme responsible for catabolizing catecholamines, and FK506 binding protein 5, a glucocorticoid receptor chaperone protein, have demonstrated robust associations with the magnitude and persistence of pain and distress following whiplash injury. ${ }^{9,69}$ The position that some people are more genetically vulnerable to pain and distress from trauma is new and potentially dangerous for insurance consumers, so we do not wish to prematurely endorse such findings as fact, as causation has yet to be firmly established. While genetics has been introduced into our model, it is with a strong caveat that considerable work remains to be done to establish its role and effects.

Context is important both from a perspective of reaction to stress and trauma and because the most common outcome of interest is patient reporting, an interpersonal transaction that necessitates inclusion of contextual variables. These variables include prevailing cultural beliefs about the experience and expression of pain and suffering, ${ }^{10,36,38,78}$ the medicolegal context within which the injury occurs, ${ }^{21,37,85}$ the quality of social support, ${ }^{90}$ and other life stressors (both recent and earlier in life). ${ }^{15}$ Importantly, the extent to which these factors are either resiliencies or vulnerabilities likely varies by context, such that they may be a vulnerability under one condition and protective under another. ${ }^{1}$ Take, for example, auto insurance coverage as a factor: adequate financial means to afford appropriate insurance coverage provided (or perceived to be provided) under a supportive client-insurer relationship may facilitate the patient's resumption of a satisfactory life trajectory. Yet under a different context, such as inadequate insurance coverage with a real or perceived adversarial client-insurer relationship, this factor may function as more of a risk than a protector. These interactive effects cannot be ignored and may explain the failings of prior models to identify universal risk/vulnerability factors, because most are likely person and context dependent.

\section{Trauma as a Stressor or "Trigger" of the Process}

In our model (FIGURE), the trauma is conceptualized as the stressor or trigger that leads to a cascade of physiological and psychological events. Squealing tires, breaking glass, sudden chaos, fear for the safety of oneself and others, personal injury, confrontation, and a series of events that include communicating with unfamiliar entities (tow truck drivers, body shops, emergency medical services, police, insurers, and possibly lawyers) all contribute to a complex tapestry of social stressors from trauma.

Whiplash itself has been defined as a mechanism of energy transfer through the tissues of the neck that is often beyond their capacity to dissipate. ${ }^{96}$ In this mechanism, some degree of tissue damage is likely and expected, the magnitude of which could range from low-grade sprain/strain of supporting soft tissues to complete tissue rupture, frank joint dislocation, 
bony fracture, or even spinal cord trauma. ${ }^{32,34,41,93}$ More recent emerging evidence suggests that some of the sequelae of WAD may be explainable as a mild traumatic brain injury (concussion) ${ }^{28}$ Regardless of the actual tissue(s) affected and the severity of injuries, such damage should lead to a cascade of physiological processes intended to repair the related tissues and restore physiological homeostasis. In our model, physiological and psychological stressors interact within a broader context of individual diatheses to influence the experience of acute trauma, pain, and recovery.

Unique to prior models, some degree of traumatic stress (here referred to as distress) is considered normal and desirable, as new evidence on posttraumatic stress disorder (PTSD) has revealed that those with no acute response, those who exhibit flat affect and dissociation, may be at equal or greater risk of psychopathology than those who exhibit an exaggerated stress response, ${ }^{123}$ challenging the validity of the traditional empirical assumption of a linear relationship between distress and outcomes. Accordingly, the right-sided path of this new model (FIGURE) allows for an adaptive and appropriately transient stress response, preparing the injured person for recovery rather than symptom persistence. Following the acute stress reaction, the person mobilizes resources supporting resilience and adaptation in the face of adversity, appropriately confronts the experience with adequate support, and eventually resumes a satisfying life trajectory. Note an important presupposition here: recovery, defined as a state of being identical to that held prior to the trauma, is not automatically assumed. Rather, the conceptualization of recovery, as defined by Walton and colleagues, ${ }^{118}$ focuses on satisfaction with perceived life trajectory, regardless of whether that trajectory is identical to its pretrauma analog.

The left side of the model (FIGURE) is akin to the vicious cycle proposed in the original FA model, but with additional considerations based on neurobiological evidence spanning the past 15-plus years. The model starts with a distress response that is maladaptive and dysregulated - including either exaggerated or blunted psychological and physiological responses, both of which may interfere with the normal inflammatory and healing processes of damaged tissue. ${ }^{40}$ Similarly, we have included in this initial st age a sense of unfairness or victimization, social scrutiny, and threat to personal safety or self-agency. A parallel pathway is also proposed here that describes subtle, but often unobserved, lesions to the central nervous system that, when present, very likely interact with peripheral or psychological mechanisms to facilitate symptom maintenance. ${ }^{32,34}$ The model then moves through primary sequelae that are often cited as clinical components of the spectrum of WAD: sensory hyperalgesia ${ }^{87}$ (local or widespread mechanical, thermal, acoustic, photic, osmic), fear of pain or movement, ${ }^{2}$ cognitive interference, ${ }^{91}$ and impaired tissue health (eg, muscle fatty infiltration, atrophy, reduced tensile strength). ${ }^{30,31,33,35}$ As the primary sequelae persist, secondary sequelae emerge that include sensorimotor incongruence (distorted body schema, disturbed proprioception, oculomotor and postural deficits), withdrawal from valued life roles, a sense of isolation, hopelessness, hypervigilance toward threat cues, and obstruction of a satisfying life trajectory. Dissociation has been included here as a potential alternative to hypervigilance. ${ }^{92}$ As these secondary sequelae persist, theory and empiricism suggest that they are precursors to nonacceptance or nonconfrontation (possibly exhibited through "doctor shopping" or other such behaviors), a sense of personal self-discrepancy (I think I'm a strong, trustworthy person, but am I?), 
diagnosable psychopathology (depression, PTSD), ${ }^{22,120}$ and hence a propensity to perceive and express greater disability. The vicious cycle continues until it is broken by appropriate support and intervention.

\section{INTEGRATION OF RECENT AND EMERGING EVIDENCE}

The purpose of this section is to provide an in-depth, but not exhaustive, narrative overview of how and why different components have been included in our proposed model.

The biomechanics held provides ample evidence supporting a link between collision parameters and potential for tissue damage ${ }^{46,119}$ that is likely to be further informed as "hard" collision data (eg, through vehicle event data recorders, dashboard-mounted cameras, Global Positioning System tracking, smartphone sensors, and other such technologies) become more accessible. While these collision and biomechanical factors have yet to be consistently associated with clinical outcomes, there can be little argument that for many people the experience of being involved in a road traffic collision (in particular, being an occupant in the vehicle that is struck) is a significant stressor ${ }^{80}$ that in our model initiates the cascade of subsequent events.

The stress response systems m humans are highly complex, integrated, and operate largely through feedback loops intended to protect the organism from further harm and, where necessary, prepare for vital survival strategies (eg, flight/fight/freeze). The unfavorable pathway in our model starts with a dysregulated or maladaptive $s$ tress response. Tire mechanisms of such may be genetic,, 969 or may be related to conditioning through prior life experience. ${ }^{123}$ Recent work has revealed that a perception of being the victim of injustice ${ }^{102,103}$ or anger management/expression style ${ }^{12,16}$ is associated with the experience and/or expression of pain and disability that can be included at this stage. The parallel pathway indicating possible involvement of the central nervous system comes from emerging evidence that WAD shares many clinical and lab-based characteristics with either mild traumatic brain injury ${ }^{28}$ or subclinical damage to spinal white matter tracts ${ }^{32,93}$ in at least a discrete number of patients. This offers a potential alternative biological pathway for the persistence of WAD symptoms that is independent of (but likely in teracts with) the personal stress reaction.

While the signs and symptoms associated with WAD are diverse and at times confusing, the model posits potential explanatory pathways that may demystify many of the more mysterious clinical presentations. Sensory hypersensitivity has become a recognized sequela of WAD. ${ }^{98}$ Several biomarkers of stress system activity, including cortisol, ${ }^{83}$ serotonin, ${ }^{88}$ and brain-derived neurotrophic factor, ${ }^{124}$ have been associated with increased sensitivity to different stimuli, representing possible explanatory pathways between s tress and hypersensitivity. Similarly, sensory processing dysfunction (eg, light, odor, sound) is a common symptom following concussion, ${ }^{6,18,23}$ and as evidence of damage to the sensory (and motor) tracts of the cervical cord continues to emerge, ${ }^{25}$ in some patients, ${ }^{32}$ central tract damage, with or without maladaptive stress responses, could explain this local or widespread mul timodal sensory hypersensitivity. 
Cognitive interference (eg, impaired concentration, memory, and higher-order functioning) is also part of the spectrum of WAD. ${ }^{96}$ The mechanisms driving these phenomena have remained unclear, but it is worth noting that they have also been associated with concussion, ${ }^{29}$ hypercortisolism, ${ }^{71}$ chronic stress, ${ }^{7}$ and PTSD,${ }^{39}$ offering some possible insights into convergence across these related conditions and potential mechanistic pathways. Fear (of movement, pain, or the unknown) rounds out the reactions in this primary sequela stage. This is supported by the findings by Kamper and colleagues, ${ }^{52}$ who de termined that fear of movement, as measured by the Tampa Scale of Kinesiophobia, could explain $41 \%$ of the association between initial pain and 3-month disability following WAD.

Evidence to support the secondary sequelae in WAD is mixed. Sensorimotor incongruence appears to be common in persis tent WAD, such as greater joint position error, ${ }^{106,108,122}$ more difficulty maintaining static postures, ${ }^{107}$ and dizziness and nausea, ${ }^{108}$ but information on the underlying mechanisms is only starting to emerge. The most likely candidates appear to be the cervical proprioceptive afferents, ${ }^{24}$ though it is too early to exclude the possibility of damage to the vestibular apparatus or mild traumatic brain injury as a result of the event. Withdrawal from physical activity or social interaction has been described in chronic pain conditions, ${ }^{114}$ as has a preoccupation with, or hypervigilance toward, bodily sensations that may indicate harm or threat. ${ }^{3}$ Concurrent experiences include a sense of isolation and experiences of stigma from others ${ }^{27}$ that represent threats to personal self-identity. ${ }^{27} \mathrm{We}$ urge caution here in assigning blame to the injured person in this regard; a possible mechanism for such preoccupation could be the frequent and recurrent assessments and evaluations to which people with persistent WAD are subjected, especially when their symptoms cannot be explained by traditional biomedical conceptualizations.

These incongruences, whether cognitive or somatic (mismatch between perception and reality of body), occur alongside a sense of obstruction of life trajectory and sense of nonrecovery or dissatisfaction with self. Temporally, hopelessness for a future that seems no longer within reach may manifest in depression, ${ }^{63}$ while dissociation or hypervigilance may function as precursors for anxiety disorders or PTSD. ${ }^{81}$ Depression, chronic pain, PTSD, and other such conditions have long been associated with hypothalamic-pituitary-adrenal axis dysregulation, ${ }^{100,104}$ sense of threat or victimization, ${ }^{70}$ and disturbed sleep, ${ }^{20,53}$ and so the cycle continues.

\section{DISCUSSION AND IMPLICATIONS}

We have presented an expanded stress-diathesis model of chronic WAD development that includes biological, psychological, and social considerations and allows each to interact in forming the individual response to trauma and clinical presentation. In many instances, the evidence is in its infancy, and in some cases has been refuted by other author groups. ${ }^{54}$ It has been presented in such a way as to endorse possible causal pathways, yet to stop short of nominating specific variables that should be explored, other than a few areas where the evidence appears particularly compelling or promising (eg, hypothalamic-pituitary-adrenal axis activity, certain genetic polymorphisms, catastrophic thinking). A separate intention is to combat a problematic but pervasive belief driven by what appears to be misinterpretation of cognitive models: that the development of chronic pain is the fault of the patient who is 
thinking wrong about his or her condition. By endorsing the concept of diatheses, we encourage recognition that no two people will respond in the exact same way to a traumatic event. Whether those reactions be driven by the experience of trauma itself, genetics, damage to key structures, prior life experiences, prevailing cultural beliefs and pressures, or (more likely) some contribution from all of these, researchers in the field are encouraged to work across traditional academic boundaries to find points of convergence that can start to unravel what continues to be a burdensome and recalcitrant problem. This will require innovation in research design and very likely a shift away from traditional randomized trials that assume equal representation of important personal factors in 2 or more treatment arms. Pragmatic trials are one means forward as a promising approach to bridge research and clinical practice. ${ }^{17}$ Even more promising is the emergence of big data and neural networks, requiring clinical researchers to collaborate with data scientists to improve predictive models that can identify potentially important interaction effects. Similarly, our model should lend greater support for " $\mathrm{N}$ of 1 " or even qualitative research designs that can uncover potentially important patient-level factors that cannot be identified in large group mean data. An additional challenge, put forth to clinicians and policy makers, is to focus on the individual patient rather than on results of population-level or group mean data when making individual patient decisions. In an era of a fully mapped human genome, cloud computing and big data, advancing artificial intelligence, and personalized medicine, it remains surprising that many in the field continue to expect a direct association between the speed of the colliding vehicle and the magnitude of symptoms on presentation. We hope presentation of this new expanded model will usher in a new era of interdisciplinary, personalized approaches to meeting the challenge of WAD.

\section{REFERENCES}

1. Alschuler KN, Kratz AL, Ehde DM. Resilience and vulnerability in individuals with chronic pain and physical disability. Rehabil Psychol. 2016;61:7-18. 10.1037/rep0000055 [PubMed: 26881303]

2. Andersen TE, Karstoft KI, Brink O, Elklit A. Paincatastrophizing and fear-avoidance beliefs as mediators between post-traumatic stress symptoms and pain following whiplash injury - a prospective cohort study. Eur J Pain. 2016;20:1241-1252. 10.1002/ejp.848 [PubMed: 26919333]

3. Asmundson GJ, Wright KD, Hadjistavropoulos HD. Hypervigilance and attentional fixedness in chronic musculoskeletal pain: consistency of findings across modified Stroop and dot-probe tasks. J Pain. 2005;6:497-506. 10.1016/j.jpain.2005.02.012 [PubMed: 16084464]

4. Barnsley L, Lord S, Bogduk N. Whiplash injury. Pain. 1994;58:283-307. 10.1016/0304-3959(94)90123-6 [PubMed: 7838578]

5. Barnsley L, Lord SM, Wallis BJ. Bogduk N. The prevalence of chronic cervical zygapophysial joint pain after whiplash. Spine (Phila Pa 1976). 1995;20:20-25; discussion 26. [PubMed: 7709275]

6. Bergemalm PO, Hennerdal S, Persson B, Lyxell B. Borg E. Perception of the acoustic environment and neuroimaging findings: a report of six cases with a history of closed head injury. Acta Otolaryngol. 2009;129:801-808. 10.1080/00016480802419099 [PubMed: 18836964]

7. Berryman C, Stanton TR, Bowering KJ, Tabor A, McFarlane A, Moseley GL. Do people with chronic pain have impaired executive function? A metaanalytical review. Clin Psychol Rev. 2014;34:563579. 10.1016/j.cpr.2014.08.003 [PubMed: 25265056]

8. Bortsov AV, Diatchenko L, McLean SA. Complex multilocus effects of catechol- $O$ methyltransferase haplotypes predict pain and pain interference 6 weeks after motor vehicle collision. Neuromolecular Med. 2014;16:83-93. 10.1007/s12017-013-8255-9 [PubMed: 23963787] 
9. Bortsov AV, Smith JE, Diatchenko L, et al. Polymorphisms in the glucocorticoid receptor cochaperone FKBP5 predict persistent musculoskeletal pain after traumatic stress exposure. Pain. 2013;154:1419-1426. 10.1016/j.pain.2013.04.037 [PubMed: 23707272]

10. Bostick GP, Ferrari R, Carroll LJ, et al. A population-based survey of beliefs about neck pain from whiplash injury, work-related neck pain, and work-related upper extremity pain. Eur J Pain. 2009;13:300-304. 10.1016/j.ejpain.2008.04.003 [PubMed: 18492612]

11. Bousema EJ, Verbunt JA, Seelen HA, Vlaeyen JW, Knottnerus JA. Disuse and physical deconditioning in the first year after the onset of back pain. Pain. 2007;130:279-286. 10.1016/ j.pain.2007.03.024 [PubMed: 17467902]

12. Bruehl S, Liu X, Burns JW, Chont M, Jamison RN. Associations between daily chronic pain intensity, daily anger expression, and trait anger expressiveness: an ecological momentary assessment study. Pain. 2012;153:2352-2358. 10.1016/j.pain.2012.08.001 [PubMed: 22940462]

13. Buitenhuis J, de Jong RJ, Jaspers JP, Groothoff JW. Work disability after whiplash: a prospective cohort study. Spine (Phila Pa 1976). 2009;34:262-267. 10.1097/BRS.0b013e3181913d07 [PubMed: 19148041]

14. Bui tenhuis J, Jaspers JP, Fidler V. Can kinesiophobia predict the duration of neck symptoms in acute whiplash? Clin J Pain. 2006;22:272-277. 10.1097/01.ajp.0000173180.54261.0a [PubMed: 16514328]

15. Burke NN, Finn DP, McGuire BE, Roche M. Psychological stress in early life as a predisposing factor for the development of chronic pain: clini cal and preclinical evidence and neurobiological mechanisms. J Neurosci Res. 2017;95:1257-1270. 10.1002/jnr.23802 [PubMed: 27402412]

16. Burns JW, Quartana PJ, Bruehl S. Anger management style moderates effects of emotion suppression during initial stress on pain and cardiovascular responses during subsequent paininduction. Ann Behav Med. 2007;34:154165. 10.1007/BF02872670 [PubMed: 17927554]

17. Califf RM, Sugarman J. Exploring the ethical and regulatory issues in pragmatic clinical trials. Clin Trials. 2015;12:436-441. 10.1177/1740774515598334 [PubMed: 26374676]

18. Capó-Aponte JE, Urosevich TG, Temme LA, Tarbett AK, Sanghera NK. Visual dysfunctions and symptoms during the subacute stage of blastinduced mild traumatic brain injury. Mil Med. 2012;177:804-813. [PubMed: 22808887]

19. Carroll LJ, Hogg-Johnson S, van der Velde G, et al. Course and prognostic factors for neck pain in the general population: results of the Bone and Joint Decade 2000-2010 Task Force on Neck Pain and Its Associated Disorders. Spine (Phila Pa 1976). 2008;33:S75-S82. 10.1097/ BRS.0b013e31816445be [PubMed: 18204403]

20. Casement MD, Harrington KM, Miller MW, Resick PA. Associations between Pittsburgh Sleep Quality Index factors and health outcomes in women with posttraumatic stress disorder. Sleep Med. 2012;13:752-758. 10.1016/j.sleep.2012.02.014 [PubMed: 22542787]

21. Cassidy JD, Carroll LJ, Côté R Lemstra M, Berglund A, Nygren A. Effect of eliminating compensation for pain and suffering on the outcome of insurance claims for whiplash injury. N Engl J Med. 2000;342:1179-1186. 10.1056/NEJM200004203421606 [PubMed: 10770984]

22. Castillo RC, Wegener ST Heins SE, Haythornthwaite JA, MacKenzie EJ, Bosse MJ. Longitudinal relationships between anxiety, depression, and pain: results from a two-year cohort study of lower extremity trauma patients. Pain. 2013;154:2860-2866. 10.1016/j.pain.2013.08.025 [PubMed: 23994104]

23. Charland-Verville V, Lassonde M, Frasnelli J. Olfaction in athletes with concussion. Am J Rhinol Allergy. 2012;26:222-226. 10.2500/ajra.2012.26.3769 [PubMed: 22643951]

24. Chen X, Treleaven J. The effect of neck torsion on joint position error in subjects with chronic neck pain. Man Ther. 2013;18:562-567. 10.1016/j.math.2013.05,015 [PubMed: 23810427]

25. Cohen-Adad J, El Mendili MM, Lehericy S, et al. Demyelination and degeneration in the injured human spinal cord detected with diffusion and magnetization transfer MRI. Neuroimage. 2011;55:1024-1033. 10.1016/j.neuroimage.2010.11.089 [PubMed: 21232610]

26. Crombez G, Vlaeyen JW, Heuts PH, Lysens R. Pain-related fear is more disabling than pain itself: evidence on the role of painrelated fear in chronic back pain disability. Pain. 1999;80:329-339. 10.1016/S0304-3959(98)00229-2 [PubMed: 10204746] 
27. De Ruddere L, Craig KD. Understanding stigma and chronic pain: a -state-of-the-art review. Pain. 2016;157:1607-1610. 10.1097/j.pain.0000000000000512 [PubMed: 26859821]

28. Elkin BS, Elliott JM, Siegmund GP. Whiplash injury or concussion? A possible biomechanical explanation for concussion symptoms in some individuals following a rear-end collision. J Orthop Sports Phys Ther. 2016;46:874-885. 10.2519/jospt.2016.7049 [PubMed: 27690834]

29. Ellemberg D, Leclerc S, Couture S, Daigle C. Prolonged neuropsychological impairments following a first concussion in female university soccer athletes. Clin J Sport Med. 2007;17:369374. 10.1097/JSM.0b013e31814c3e3e [PubMed: 17873549]

30. Elliott J, Pedler A, Kenardy J, Galloway G, Jull G, Sterling M. The temporal development of fatty infiltrates in the neck muscles following whiplash injury: an association with pain and posttraumatic stress. PLoS One. 2011;6:e21194 10.1371/journal.pone.0021194 [PubMed: 21698170]

31. Elliott JM, Courtney DM, Rademaker A, Pinto D, Sterling MM, Parrish TB. The rapid and progressive degeneration of the cervical multifidus in whiplash: an MRI study of fatty infiltration. Spine (Phila Pa 1976). 2015;40:E694-E700. 10.1097/BRS.0000000000000891 [PubMed: 25785961]

32. Elliott JM, Dewald JR Hornby TG, Walton DM, Parrish TB. Mechanisms underlying chronic whiplash; contributions from an incomplete spinal cord injury? Pain Med. 2014;15:1938-1944. https://doi.org/10.1111/pme.12518 [PubMed: 25139822]

33. Elliott JM, Noteboom JT Flynn TW, Sterling M. Characterization of acute and chronic whiplashassociated disorders. J Orthop Sports Phys Ther. 2009;39:312-323. 10.2519/jospt.2009.2826 [PubMed: 19411765]

34. Elliott JM, Pedler AR, Cowin G, Sterling M, McMahon K. Spinal cord metabolism and muscle water diffusion in whiplash. Spinal Cord. 2012;50:474476. 10.1038/sc.2011.17 [PubMed: 21383759]

35. Elliott JM, Pedler AR, Jull GA, Van Wyk L, Galloway GG, O’Leary SP. Differential changes in muscle composition exist in traumatic and nontraumatic neck pain. Spine (Phila Pa 1976). 2014;39:39-47. 10.1097/BRS.0000000000000033 [PubMed: 24270932]

36. Ferrari R, Constantoyannis C, Papadakis N. Laypersons' expectation of the sequelae of whiplash injury: a cross-cultural comparative study between Canada and Greece. Med Sci Monit. 2003;9:CR120-CR124. [PubMed: 12640340]

37. Ferrari R, Kwan 0, Russell AS, Pearce JM, Schrader H. The best approach to the problem of whiplash? One ticket to Lithuania, please. Clin Exp Rheumatol. 1999;17:321-326. [PubMed: 10410265]

38. Ferrari R, Obelieniene D, Russell A, Darlington R Gervais R, Green P. Laypersons' expectation of the sequelae of whiplash injury. A cross-cultural comparative study between Canada and Lithuania. Med Sci Monit. 2002;8:CR728-CR734. [PubMed: 12444375]

39. Flaks MK, Malta SM, Almeida PP et al. Attentional and executive functions are differentially affected by post-traumatic stress disorder and trauma. J Psychiatr Res. 2014;48:32-39. 10.1016/ j.jpsychires.2013.10.009 [PubMed: 24199652]

40. Gouin JP Kiecolt-Glaser JK. The impact of psychological stress on wound healing: methods and mechanisms. Immunol Allergy Clin North Am. 2011;31:81-93. 10.1016/j.iac.2010.09.010 [PubMed: 21094925]

41. Guéz M, Hildingsson C, Rosengren L, Karlsson K, Tooianen G. Nervous tissue damage markers in cerebrospinal fluid after cervical spine injuries and whiplash trauma. J Neurotrauma. 2003;20:853-858. 10.1089/089771503322385782 [PubMed: 14577863]

42. Guzman J, Hurwitz EL, Carroll LJ, et al. A new conceptual model of neck pain: linking onset, course, and care: the Bone and Joint Decade 2000-2010 Task Force on Neck Pain and Its Associated Disorders. Spine (Phila Pa 1976). 2008;33;S14-S23. 10.1097/BRS.0b013e3181643efb [PubMed: 18204387]

43. Hartling L, Brison RJ, Ardern C, Pickett W. Prognostic value of the Quebec Classification of Whiplash-Associated Disorders. Spine (Phila Pa 1976). 2001;26:36-41. [PubMed: 11148643]

44. Hill AB. The environment and disease: association or causation? Proc R Soc Med. 1965;58:295300. [PubMed: 14283879] 
45. Ishikawa S, Yokoyama M, Mizobuchi S, Hashimoto H, Moriyama E, Morita K. Epidural blood patch therapy for chronic whiplash-associated disorder. Anesth Analg. 2007;105:809-814. 10.1213/01.ane.0000271922.04981.33 [PubMed: 17717243]

46. Ivancic PC. Mechanisms and mitigation of head and spinal injuries due to motor vehicle crashes. J Orthop Sports Phys Ther. 2016;46:826-833. 10.2519/jospt.2016.6716 [PubMed: 27594659]

47. Joslin CC, Khan SN, Bannister GC. Long-term disability after neck injury. A comparative study. J Bone Joint Surg Br. 2004;86:1032-1034. [PubMed: 15446533]

48. Jull G, Kenardy J, Hendrikz J, Cohen M, Sterling M. Management of acute whiplash: a randomized controlled trial of multidisciplinary stratified treatments. Pain. 2013;154:1798-1806. 10.1016/j.pain.2013.05.041 [PubMed: 23726933]

49. Kaale BR, Krakenes J, Albrektsen G, Wester K. Active range of motion as an indicator for ligament and membrane lesions in the upper cervical spine after a whiplash trauma. J Neurotrauma. 2007;24:713-721. 10.1089/neu.2006.0193 [PubMed: 17439353]

50. Kaale BR, Krakenes J, Albrektsen G, Wester K. Head position and impact direction in whiplash injuries: associations with MRI-verified lesions of ligaments and membranes in the upper cervl cal spine. J Neurotrauma. 2005;22:1294-1302. 10.1089/neu.2005.22.1294 [PubMed: 16305317]

51. Kaale BR, Krakenes J, Albrektsen G, Wester K. Whiplash-associated disorders impairment rating: Neck Disability Index score according to severity of MRI findings of ligaments and membranes in the upper cervical spine. J Neurotrauma. 2005;22:466-475. 10.1089/neu.2005.22.466 [PubMed: 15853463]

52. Kamper SJ, Maher CG, Menezes Costa LC, McAuley JH, Hush JM. Sterling M. Does fear of movement mediate the relationship between pain intensity and disability in patients following whiplash injury? A prospective longitudinal study. Pain. 2012;153:113-119. 10.1016/ j.pain.2011.09.023 [PubMed: 22054600]

53. Karaman S, Karaman T, Dogru S, et al. Prevalence of sleep disturbance in chronic pain. Eur Rev Med Pharmacol Sci. 2014;18:2475-2481. [PubMed: 25268092]

54. Kneebone II, Guerrier S, Dunmore E, Jones E, Fife-Schaw C. A longitudinal examination of the hopelessness theory of depression in people who have multiple sclerosis. Behav Neurol. 2015:2015:190405 10.1155/2015/190405 [PubMed: 26290622]

55. Krakenes J, Kaale BR. Magnetic resonance imaging assessment of craniovertebral ligaments and membranes after whiplash trauma. Spine (Phila Pa 1976). 2006;31:2820-2826. 10.1097/01.brs.0000245871.15696.1f [PubMed: 17108836]

56. Krakenes J, Kaale BR, Moen G, Nordli H, Gilhus NE, Rorvik J. MRI assessment of the alar ligaments in the late stage of whiplash injury - a study of structural abnormalities and observer agreement. Neuroradiology. 2002;44:617-624. 10.1007/s00234-002-0799-6 [PubMed: 12136365]

57. Krakenes J, Kaale BR, Moen G, Nordli H, Gilhus NE, Rorvik J. MRI of the tectorial and posterior atlanto-occipital membranes in the late stage of whiplash injury. Neuroradiology. 2003;45:585591. 10.1007/s00234-003-1036-7 [PubMed: 12904927]

58. Krakenes J, Kaale BR, Nordli H, Moen G, Rorvik J, Gilhus NE. MR analysis of the transverse ligament in the late stage of whiplash injury. Acta Radiol. 2003;44:637-644. 10.1046/ j,1600-0455.2003.00134.x [PubMed: 14616208]

59. Lamb SE, Gates S, Williams MA, et al. Emergency department treatments and physiotherapy for acute whiplash: a pragmatic, two-step, randomised controlled trial. Lancet. 2013;381:546-556. 10.1016/S0140-6736(12)61304-X [PubMed: 23260167]

60. Leeuw M, Goossens ME, Linton SJ, Crombez G, Boersma K, Vlaeyen JW. The fear-avoidance model of musculoskeletal pain: current state of scientific evidence. J Behav Med. 2007;30:77-94. 10.1007/s10865-006-9085-0 [PubMed: 17180640]

61. Lirinstaedt SD, Riker KD, Walker MG, et al. MicroRNA 320a predicts chronic axial and widespread pain development following motor vehicle collision in a stress-dependent manner. J Orthop Sports Phys Ther. 2016;46:911-919. 10.2519/jospt.2016.6944 [PubMed: 27690835]

62. Lirinstaedt SD, Walker MG, Riker KD, et al. Genetic variant rs3750625 in the 3'UTR of ADRA2A affects stress-dependent acute pain severity after trauma and alters a microRNA-34a regulatory site. Pain. 2017;158:230-239. 10.1097/j.pain.0000000000000742 [PubMed: 27805929] 
63. Liu RT Kleiman EM, Nestor BA, Cheek SM. The hopelessness theory of depression: a quartercentury in review. Clin Psychol (New York). 2015; 22:345-365. https://doi.org/10.1111/ cpsp. 12125

64. Lord SM, Barnsley L, Bogduk N. Percutaneous radiofrequency neurotomy in the treatment of cervical zygapophysial joint pain: a caution. Neurosurgery. 1995;36:732-739. [PubMed: 7596504]

65. Lord SM, Barnsley L, Wallis BJ, Bogduk N. Chronic cervical zygapophysial joint pain after whiplash. A placebo-controlled prevalence study. Spine (Phila Pa 1976). 1996;21:1737-1744; discussion 1744-1745. [PubMed: 8855458]

66. Lord SM, Barnsley L, Wallis BJ, McDonald GJ, Bogduk N. Percutaneous radio-frequency neurotomy for chronic cervical zygapophyseal-joint pain. N Engl J Med. 1996;335:1721-1726. https://doi.org/10.1056/NEJM199612053352302 [PubMed: 8929263]

67. Martin AL, Halket E, Asmundson GJ, Flora DB, Katz J. Posttraumatic stress symptoms and the diathesis-stress model of chronic pain and disability in patients undergoing major surgery. Clin $\mathrm{J}$ Pain. 2010;26:518-527. 10.1097/AJP.0b013e3181el5b98 [PubMed: 20551727]

68. McLean SA. The potential contribution of stress systems to the transition to chronic whiplashassociated disorders. Spine (Phila Pa 1976). 2011;36: S226-S232. 10.1097/ BRS.0b013e3182387fb4 [PubMed: 22020617]

69. McLean SA, Diatchenko L, Lee YM, et al. Catechol $O$-methyltransferase haplotype predicts immediate musculoskeletal neck pain and psychological symptoms after motor vehicle collision. $\mathrm{J}$ Pain. 2011;12:101-107. 10.1016/j.jpain.2010.05.008 [PubMed: 20688576]

70. McParland J, Hezseltine L, Serpell M, Eccleston C, Stenner P. An investigation of constructions of justice and injustice in chronic pain: a Q-methodology approach. J Health Psychol. 2011;16:873883. 10.1177/1359105310392417 [PubMed: 21430131]

71. Michaud K, Forget H, Cohen H. Chronic glucocorticoid hypersecretion in Cushing's syndrome exacerbates cognitive aging. Brain Cogn. 2009;71:1-8. 10.1016/j.bandc.2009.02.013 [PubMed: 19428166]

72. Murray CJ, Barber RM, Foreman KJ, et al. Global, regional, and national disability-adjusted life years (DALYs) for 306 diseases and injuries and healthy life expectancy (HALE) for 188 countries, 1990-2013: quantifying the epidemiological transition. Lancet. 2015;386:2145-2191. 10.1016/S0140-6736(15)61340-X [PubMed: 26321261]

73. Murray CJ, Vos T, Lozano R, et al. Disabilityadjusted life years (DALYs) for 291 diseases and injuries in 21 regions, 1990-2010: a systematic analysis for the Global Burden of Disease Study 2010. Lancet. 2012;380:2197-2223. 10.1016/S0140-6736(12)61689-4 [PubMed: 23245608]

74. Myran R, Kvistad KA, Nygaard OP, Andresen H, Folvik M, Zwart JA. Magnetic resonance imaging assessment of the alar ligaments in whiplash injuries: a case-control study. Spine (Phila Pa 1976). 2008;33:2012-2016. 10.1097/BRS.0b013e31817bb0bd [PubMed: 18708935]

75. Myran R, Zwart JA, Kvistad KA, et al. Clinical characteristics, pain, and disability in relation to alar ligament MRI findings. Spine (Phila Pa 1976). 2011;36:E862-E867. 10.1097/ BRS.0b013e3181ffldde [PubMed: 21289550]

76. Naumann RB, Dellinger AM, Zaloshnja E, Lawrence BA, Miller TR. Incidence and total lifetime costs of motor vehicle-related fatal and nonfatal injury by road user type, United States, 2005. Traffic Inj Prev. 2010;11:353-360. 10.1080/15389588.2010.486429 [PubMed: 20730682]

77. Newton BJ, Southall JL, Raphael JH, Ashford RL, LeMarchand K. A narrative review of the impact of disbelief in chronic pain. Pain Manag Nurs. 2013;14:161-171. 10.1016/ j.pmn.2010.09.001 [PubMed: 23972867]

78. Ng TS, Bostick G, Pedler A, Buchbinder R, Vicenzino B, Sterling M. Laypersons' expectations of recovery and beliefs about whiplash injury: a cross-cultural comparison between Australians and Singaporeans. Eur J Pain. 2013;17:1234-1242. 10.1002/j.1532-2149.2012.00265.x [PubMed: 23255308]

79. Nieto R, Miro J, Huguet A. The fear-avoidance model in whiplash injuries. Eur J Pain. 2009;13:518-523. 10.1016/j.ejpain.2008.06.005 [PubMed: 18640860]

80. Norris FH. Epidemiology of trauma: frequency and impact of different potentially traumatic events on different demographic groups. J Consult Clin Psychol. 1992;60:409-418. [PubMed: 1619095] 
81. Otis C, Marchand A, Courtois F. Peritraumatic dissociation as a mediator of peritraumatic distress and PTSD: a retrospective, cross-sectional study. J Trauma Dissociation. 2012;13:469-477. 10.1080/15299732.2012.670870 [PubMed: 22651680]

82. Otte A. PET with ${ }^{18}$ fluorodeoxyglucose and hexamethylpropylene amine oxime SPECT in late whiplash syndrome [letter]. Neurology. 1999;52:1107-1108. 10.1212/WNL.52.5.1106-b

83. Paananen M, O'Sullivan P, Straker L, et al. A low cortisol response to stress is associated with musculoskeletal pain combined with increased pain sensitivity in young adults: a longitudinal cohort study. Arthritis Res Ther. 2015;17:355 10.1186/s13075-015-0875-z [PubMed: 26654189]

84. Parsons S, Harding G, Breen A, et al. The influence of patients' and primary care practitioners' beliefs and expectations about chronic musculoskeletal pain on the process of care: a systematic review of qualitative studies. Clin J Pain. 2007;23:91-98. 10.1097/01.ajp.0000210947.34676.34 [PubMed: 17277650]

85. Partheni M, Constantoyannis C, Ferrari R, Nikiforidis G, Voulgaris S, Papadakis N. A prospective cohort study of the outcome of acute whiplash injury in Greece. Clin Exp Rheumatol. 2000;18:6770. [PubMed: 10728446]

86. Pedler A, Kamper SJ, Sterling M. Addition of posttraumatic stress and sensory hypersensitivity more accurately estimates disability and pain than fear avoidance measures alone after whiplash injury. Pain. 2016;157:1645-1654. 10.1097/j.pain.0000000000000564 [PubMed: 27007066]

87. Pedler A, Sterling M. Patients with chronic whiplash can be subgrouped on the basis of symptoms of sensory hypersensitivity and posttraumatic stress. Pain. 2013;154:1640-1648. 10.1016/ j.pain.2013.05.005 [PubMed: 23707284]

88. Pickering G, Januei F. Dubray C, Eschalier A. Serotonin and experimental pain in healthy young volunteers. Clin J Pain. 2003;19:276-279. [PubMed: 12840623]

89. Pobereskin LH. Whiplash following rear end colli sions: a prospective cohort study. J Neurol Neurosurg Psychiatry. 2005;76:1146-1151. 10.1136/jnnp.2004.049189 [PubMed: 16024895]

90. aichle KA P, Romano JM, Jensen MR Partner responses to patient pain and well behaviors and their relationship to patient pain behavior, functioning, and depression. Pain. 2011;152:82-88. 10.1016/j.pain.2010.09.015 [PubMed: 20947249]

91. Robinson JP, Burwinkle T, Turk DC. Perceived and actual memory, concentration, and attention problems after whiplash-associated disorders (grades I and II): prevalence and predictors. Arch Phys Med Rehabil. 2007;88:774-779. 10.1016/j.apmr.2007.03.004 [PubMed: 17532901]

92. Şar V, Akyüz G, Doğan 0. Prevalence of dissociative disorders among women in the general population. Psychiatry Res. 2007;149:169-176. 10.1016/j.psychres.2006.01.005 [PubMed: 17157389]

93. Smith AC, Parrish TB, Hoggarth MA, et al. Potential associations between chronic whiplash and incomplete spinal cord injury. Spinal Cord Ser Cases. 2015:1:15024 10.1038/scsandc.2015.24

94. Smith AD, Jull G, Schneider G, et al. Cervical radiofrequency neurotomy reduces psychological features in individuals with chronic whiplash symptoms. Pain Physician. 2014;17:265-274. [PubMed: 24850108]

95. Smith AD, Jull G, Schneider GM, Frizzell B, Hooper RA, Sterling M. Modulation of cervical facet joint nociception and pain attenuates physical and psychological features of chronic whiplash: a prospective study. PM R. 2015;7:913-921. 10.1016/j.pmrj.2015.03.014 [PubMed: 25805617]

96. Spitzer WO, Skovron ML, Salmi LR, et al. Scientific monograph of the Quebec Task Force on Whiplash-Associated Disorders: redefining "whiplash" and its management. Spine (Phila Pa 1976). 1995;20:1S-73S. [PubMed: 7604354]

97. Sterling M. A proposed new classification system for whiplash associated disorders-implications for assessment and management. Man Ther. 2004;9:60-70. 10.1016/j.math2004.01.006 [PubMed: 15040964]

98. Sterling M, Jull G, Vicenzino B, Kenardy J. Sensory hypersensitivity occurs soon after whiplash injury and is associated with poor recovery. Pain. 2003;104:509-517. 10.1016/ S0304-3959(03)00078-2 [PubMed: 12927623]

99. Sterner Y, Toolanen G, Knibestol M, Gerdle B, Hiidingsson C. Prospective study of trigeminal sensibility after whiplash trauma. J Spinal Disord. 2001;14:479-486. [PubMed: 11723396] 
100. Steudte-Schmiedgen S, Stalder T, Schönfeld S, et al. Hair cortisol concentrations and cortisol stress reactivity predict PTSD symptom increase after trauma exposure during military deployment. Psychoneuroendocrinology. 2015;59:123-133. https://doi.Org/10.1016/ j.psyneuen.2015.05.007 [PubMed: 26072152]

101. Sturgeon JA, Zautra AJ. State and trait pain catastrophizing and emotional health in rheumatoid arthritis. Ann Behav Med. 2013;45:69-77. 10.1007/s12160-012-9408-z [PubMed: 22915012]

102. Sullivan MJ, Adams H, Martel MO, Scott W, Wideman I Catastrophizing and perceived injustice: risk factors for the transition to chronicity after whiplash injury. Spine (Phila Pa 1976), 2011;36:S244-S249. 10.1097/BRS.0b013e3182387fed [PubMed: 22020619]

103. Sullivan MJ, Thibault P, Simmonds MJ, Milioto M, Cantin AP, Velly AM. Pain, perceived injustice and the persistence of post-traumatic stress symptoms during the course of rehabilitation for whiplash injuries. Pain. 2009;145:325-331. 10.1016/j.pain.2009.06.031 [PubMed: 19643543]

104. Tanriverdi F, Karaca Z, Unluhizarci K, Kelestimur F. The hypothalamo-pituitary-adrenal axis in chronic fatigue syndrome and fibromyalgia syndrome. Stress. 2007;10:13-25. 10.1080/10253890601130823 [PubMed: 17454963]

105. Taylor JR, Twomey LT Kakulas BA. Dorsal root ganglion injuries in 109 blunt trauma fatalities. Injury. 1998;29:335-339. 10.1016/S0020-1383(98)80027-2 [PubMed: 9813674]

106. Treleaven J, Jull G, LowChoy N. The relationship of cervical joint position error to balance and eye movement disturbances in persistent whiplash. Man Ther. 2006;11:99-106. 10.1016/ j.math.2005.04.003 [PubMed: 15919229]

107. Treleaven J, Jull G, Lowchoy N. Standing balance in persistent whiplash: a comparison between subjects with and without dizziness. J Rehabil Med. 2005;37:224-229. 10.1080/16501970510027989 [PubMed: 16024478]

108. Treleaven J, Jull G, Sterling M. Dizziness and unsteadiness following whiplash injury; characteristic features and relationship with cervical joint position error. J Rehabil Med. 2003;35:36-43. 10.1080/16501970306109 [PubMed: 12610847]

109. Turk DC. A diathesis-stress model of chronic pain and disability following traumatic injury. Pain Res Manag. 2002;7:9-19. [PubMed: 16231063]

110. United Kingdom Ministry of Justice. Reforming the Soft Tissue Injury ('Whiplash') Claims Process; A Consultation on Arrangements Concerning Personal Injury Claims in England and Wales. London, UK: United Kingdom Ministry of Justice; 2016.

111. Vlaeyen JW, Linton SJ. Fear-avoidance and its consequences in chronic musculoskeletal pain: a state of the art. Pain. 2000;85:317-332. 10.1016/S0304-3959(99)00242-0 [PubMed: 10781906]

112. Vlaeyen JW, Linton SJ. Fear-avoidance model of chronic musculoskeletal pain: 12 years on. Pain. 2012;153:1144-1147. 10.1016/j.pain.2011.12.009 [PubMed: 22321917]

113. Wade JB, Riddle DL, Thacker LR. Is pain catastrophizing a stable trait or dynamic state in patients scheduled for knee arthroplasty? Clin J Pain. 2012;28:122-128. 10.1097/ AJP.0b013e318226c3e2 [PubMed: 22001663]

114. Wallace LS, Wexler RK, McDougle L, Miser WF, Haddox JD. Voices that may not otherwise be heard: a qualitative exploration into the perspectives of primary care patients living with chronic pain. J Pain Res. 2014;7:291-299. 10.2147/JPR.S62317 [PubMed: 24940079]

115. Wallis BJ, Lord SM, Bogduk N. Resolution of psychological distress of whiplash patients following treatment by radiofrequency neurotomy: a randomised, double-blind, placebocontrolled trial. Pain. 1997;73:15-22. 10.1016/S0304-3959(97)00060-2 [PubMed: 9414052]

116. Walton DM, Carroll LJ, Kasch H, et al. An overview of systematic reviews on prognostic factors in neck pain: results from the International Collaboration on Neck Pain (ICON) project. Open Orthop J. 2013;7:494-505. 10.2174/1874325001307010494 [PubMed: 24115971]

117. Walton DM, MacDermid JC, Giorgianni AA, Mascarenhas JC, West SC, Zammit CA. Risk factors for persistent problems following acute whiplash Injury: update of a systematic review and meta-analysis. J Orthop Sports Phys Ther. 2013;43:3143. 10.2519/jospt.2013.4507 [PubMed: 23322093]

118. Walton DM, MacDermid JC, Nielson W. Recovery from acute injury: clinical, methodological and philosophical considerations. Disabil Rehabil. 2010;32:864-874. 10.3109/09638280903349511 [PubMed: 19852703] 
119. Walton DM, Pretty J, MacDermid JC, Teasell RW. Risk factors for persistent problems following whiplash injury: results of a systematic review and meta-analysis. J Orthop Sports Phys Ther. 2009;39:334-350. 10.2519/jospt.2009.2765 [PubMed: 19411766]

120. Waters SJ, Keefe FJ, Strauman TJ. Self-discrepancy in chronic low back pain: relation to pain, depression, and psychological distress. J Pain Symptom Manage. 2004;27:251-259. 10.1016/ j.jpainsymman.2003.07.001 [PubMed: 15010103]

121. Wideman TH, Adams H, Sullivan MJ. A prospective sequential analysis of the fear-avoidance model of pain. Pain. 2009;145:45-51. 10.1016/j.pain.2009.04.022 [PubMed: 19477072]

122. Woodhouse A, Vasseljen O. Altered motor control patterns in whiplash and chronic neck pain. BMC Musculoskelet Disord. 2008;9:90 10.1186/1471-2474-9-90 [PubMed: 18570647]

123. Zaba M, Kirmeier T, lonescu IA, et al. Identification and characterization of HPA-axis reactivity endophenotypes in a cohort of female PTSD patients. Psychoneuroendocrinology. 2015;55:102_ 115. 10.1016/j.psyneuen.2015.02.005 [PubMed: 25745955]

124. Zanette SA, Dussan-Sarria JA, Souza A, Deitos A, Torres IL, Caumo W. Higher serum S100B and BDNF levels are correlated with a lower pressure-pain threshold in fibromyalgia. Mol Pain. 2014;10:46 10.1186/1744-8069-10-46 [PubMed: 25005881] 


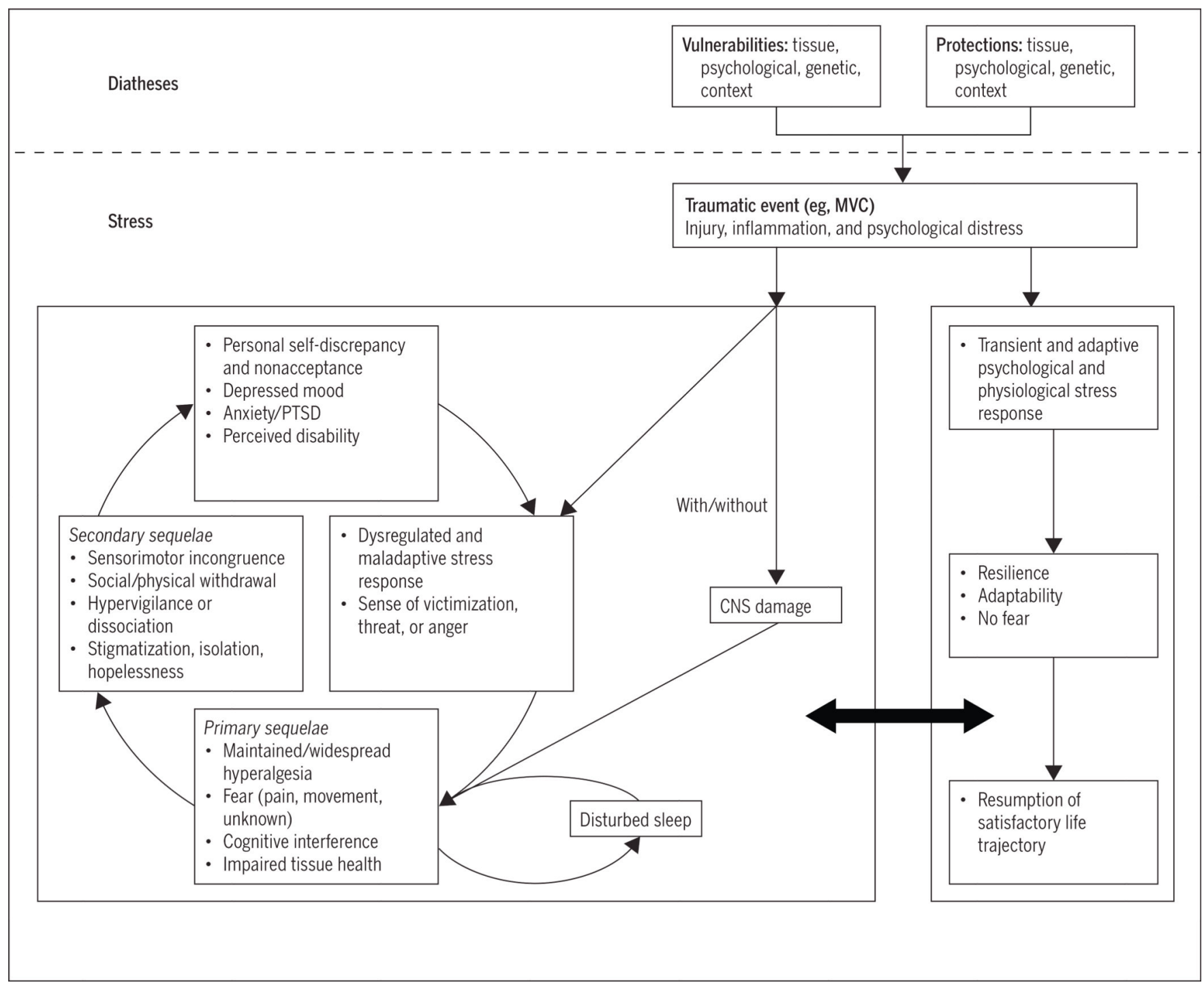

FIGURE.

An integrated biopsychosocial model describing potential mechanisms for the onset and maintenance of persistent pain and disability following acute trauma. Abbreviations: CNS, central nervous system; MVC, motor vehicle collision; PTSD, posttraumatic stress disorder. 

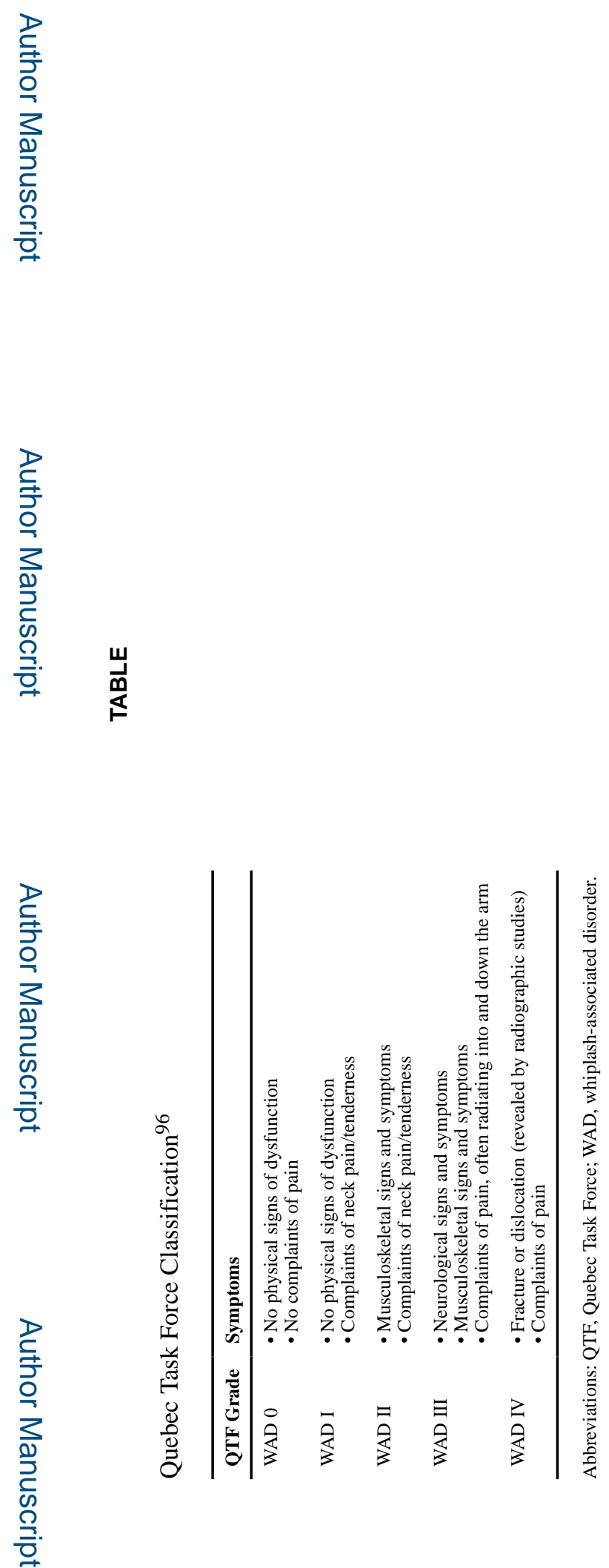

J Orthop Sports Phys Ther. Author manuscript; available in PMC 2020 July 10. 